\title{
Characteristics of Acute Flaccid Paralysis Reported by the Surveillance System and Verified by WHO Officer in Akwa Ibom State-Nigeria, 2006-2012
}

\author{
Bassey Enya Bassey1 ${ }^{*}$, Vaz Gama Rui1, Alex Ntale Gasasira1, Mkanda Pascal1, \\ Goitom Weldegbriel1, Ticha Johnson Mulum¹, Sylvester T. Maleghemi'1, \\ Emem Abasi Bassey ${ }^{2}$ \\ ${ }^{1}$ World Health Organisation, Abuja, Nigeria \\ ${ }^{2}$ Ministry of Health, Uyo, Nigeria \\ Email: ․ㅡassey69@yahoo.com, ruivaz@who.int, gasasiraa@yahoo.co.uk, Mkandap@who.int, \\ weldegebrielg@who.int, TICHAJ@who.int, maleghemis@who.int, basseyemem@yahoo.com
}

Received 3 September 2014; revised 20 October 2014; accepted 3 November 2014

Copyright (C) 2014 by authors and Scientific Research Publishing Inc.

This work is licensed under the Creative Commons Attribution International License (CC BY).

http://creativecommons.org/licenses/by/4.0/

(c) (i) Open Access

\section{Abstract}

Background: Acute Flaccid Paralysis (AFP) was adopted by World Health Organization (WHO) in 1988 as a key pillar used in monitoring progress towards the global polio eradication initiative. High quality AFP surveillance is essential to support this global initiative. We applied recently developed case verification methods for the quantitative evaluation of AFP cases reported to the surveillance systems to evaluate the quality of AFP reports in Akwa Ibom State, Nigeria. Objectives: The aim of this study is to identify the demographic, clinical and epidemiological attributes and quality of acute flaccid paralysis surveillance. Methods: All AFP cases reported in children 0 - 14 years during January 2006 to December 2012 were investigated and verified by WHO surveillance officers, using standard questionnaire. Two stool samples 24 - 48 hours apart from a total of 1184 AFP cases were collected within 14 days of onset of paralysis with the prior oral/verbal informed consent and transported to the national polio laboratory under reverse cold chain. Result: In all, $885 / 1184$ representing $75 \%$ of the AFP cases reported were verified by WHO officers in the period under review. Overall, 534/885 (60.3\%) of AFP cases had more than $>3$ doses of Oral Polio Vaccine (OPV), while 196/885 $(22.2 \%)$ received 3 dose of OPV and 128/885 (14.5\%) received between 1 - 2 doses of OPV. It was interesting that $27 / 885(3 \%)$ never received OPV before. Overall, $743 / 885(84.0 \%)$ were reported within $\leq 14$ days of paralysis onset, while $142 / 885(16 \%)$

${ }^{*}$ Corresponding author.

How to cite this paper: Bassey, B.E., et al. (2014) Characteristics of Acute Flaccid Paralysis Reported by the Surveillance System and Verified by WHO Officer in Akwa Ibom State-Nigeria, 2006-2012. Health, 6, 2602-2610. 
were reported after $\geq 14$ days of paralysis onset. In total, 797/885 $(90.1 \%)$ of cases were found to have fever at the onset of paralysis; paralysis was found to be asymmetric in $805 / 885(91 \%)$. Wasting or diminished muscle tone was observed in $34.0 \%$ of cases verified, while deep tendon reflexes were good (normal) in $\mathbf{7 9 \%}$ of cases. Gullain-Barre syndrome was observed in $50.9 \%$ of the reported cases followed by injection neuritis $(25.0 \%)$ and transverse myelitis $(2.0 \%)$. However, other causes recorded $\mathbf{2 2 . 1 \%}$. The legs $(\mathbf{9 0 . 2 \% )}$ ) are the parts of the body mostly affected, while arm recorded $9.8 \%$ of the AFP cases reported and verified. Conclusions: The result of this study indicates that the characterization of AFP cases reported to the surveillance network could provide better understanding of age, and sex distribution, common clinical causes of AFP and impact of distance to health facilities on the health seeking behaviours of AFP cases.

\section{Keywords}

Acute Flaccid Paralysis, Surveillance, Verification

\section{Introduction}

The Global Polio Eradication Initiative commenced in 1988 following the adoption of a resolution to eradicate poliomyelitis (polio) at the World Health Assembly [1] [2]. The worldwide polio eradication campaign has been successful in achieving a 99\% reduction in the global incidence of polio since 1988 [3]. The number of countries that have not yet interrupted indigenous transmission of wild poliovirus reduces to 3 in 2012 [4], although the final stages of eradication are proving challenging [5].

Acute Flaccid Paralysis (AFP) surveillance is the cornerstone of successful polio control or eradication programmes as it enables programme managers to monitor the effectiveness of intervention strategies and can help to identify populations that require continuing interventions where surveillance gaps exit. World Health Organization (WHO) targets for acute flaccid paralysis (AFP) surveillance, including the notification of a minimum rate of AFP among children, and the verification of reported cases are used to assess the adequacy or quality of AFP surveillance for the detection of poliovirus infection. High quality surveillance for poliovirus infection is essential to support global disease eradication efforts. The verification is done by WHO surveillance officer. The investigating officer physically observes the affected case and interview the parent or caretaker. The investigator who systematically follows instructions contained in the State Verification form and the objective is to ensure that reported cases are consistent with the AFP case definition, total number of OPV doses received by the child, and date of paralysis onset as indicated in the original case investigation form [6]. The aim of this study is to identify the demographic, clinical, epidemiological attributes and quality of acute flaccid paralysis surveillance.

\section{Methods}

\section{Study Area}

The study was conducted in Akwa Ibom State, Nigeria. The state has one WHO surveillance officer, thirty one (31) disease surveillance and notification officers, one hundred and eighty four (184) surveillance focal persons in designated reporting sites and seven hundred and thirty eight (738) community informants involved in the surveillance network. The last case of wild polio virus type 1 was detected in October 2001.

Study design: This is a retrospective descriptive study design making use of secondary data from all suspected cases of AFP reported to the WHO surveillance system.

Study population: The study population include all reported AFP cases among children under 15 years old that were verified by the WHO surveillance officers and any case that was not verified for any reason was excluded in the study.

Data Collection Methods: The national AFP case-base verification form was adapted for data collection. Additional information on socio-demographic and economic data was obtained from each patient at the point of verifications. All data were collected by the WHO surveillance officers. 
Oral/verbal informed consent was obtained from parents/caregivers before sample collection.

All AFP cases reported in children aged $<15$ years were detected through active surveillance with a network of surveillance officers in all 31 Local Government Areas (districts) through out the state from January 2006 to December 2012. Two stool samples 24 - 48 hours apart were collected within 14 days of onset of paralysis from each case. Patient information was recorded on a standard questionnaire including demographic details, date of onset of paralysis and clinical presentation like fever at the onset of paralysis, symmetry of paralysis, location of paralysis, time duration for paralysis progression to peak and vaccination status using oral polio vaccine. Specimens were transported to the National Polio Reference Laboratory, University of Ibadan in good condition using reverse cold chain (cold chain maintained container not leaking, good specimen quality and adequate quantity). Sixty-day follow-up reports for inadequate cases (stool specimen was collected $>14$ days of paralysis onset) were obtained through the same network using standard questionnaire. Laboratory results were received and feedback provided to clinicians and caregivers. All data collected was properly cross checked for errors, poor information, and/or missing information. Data was entered and analysed using the Epi Info software version 3.3.2 and Excel version 8.0.

\section{Results}

Table 1 Indicates the performance indicators of AFP cases reported to the surveillance system, 2006-2012.

Most countries implementing AFP surveillance strive to meet the WHO target of at least one case of AFP reported each year per 100,000 children under 15 years old, although there can be significant variability at the subnational level. In this study the target of $\geq 2$ AFP cases per 100,000 was consistently achieved from 3.9 in 2006 to 12.14 per 100,000 population in 2012, while the proportion of AFP cases with 2 stool specimen collected within 14 days of onset of paralysis remain consistently above the target of $\geq 80 \%$.

Table 2 Illustrates the social demographic characteristic of AFP cases report and verified between 2006 and 2012.

In total, 1184 AFP cases were reported through the surveillance network system in the state from January 2006 to September, 2012.

In the period 2006-2012, the number of AFP cases verified was 885/1184 (75\%); (target $\geq 80 \%)$.

Three age categories were incorporated in this study. We evaluated those less than 60 months, 60 months to less than 120 months, and 120 months or more. Those less than 60 months accounted for the largest proportion of cases (94.4\%), while $4.9 \%$ of cases reported were seen in those aged 60 - 120 months.

The sex distribution pattern of the AFP cases showed that $51.1 \%$ of the cases were seen in Female, while their male counterpart recorded $48.9 \%$.

Urban-rural settings also affected the distribution of cases reported. Study results show that more people in rural areas 746 (84.3\%) were affected, while those in urban setting recorded 139 (15.7\%).

Educationally, those subjects who had no formal education 446 (50.0\%) recorded the highest number of cases, primary school leavers recorded $227(26.0 \%)$, this was closely followed by secondary school leavers, and tertiary school leavers recorded the least 35 (4.0\%).

Overall, 534/885 (60.3\%) of AFP cases had more than 3 doses of Oral Polio Vaccine (OPV), while 196/885 (22.2\%) received 3 dose of OPV and 128/885 (14.5\%) received between 1 - 2 doses of OPV, it is interesting that 27/885 (3\%) never received OPV before.

Table 1. AFP the surveillance Performance, 2006-2012.

\begin{tabular}{|c|c|c|c|}
\hline Year & Number of cases reported & No Polio AFP rate & Stool Adequacy (\%) \\
\hline 2006 & 70 & 3.9 & 87 \\
\hline 2007 & 84 & 5 & 92 \\
\hline 2008 & 100 & 5.1 & 95 \\
\hline 2009 & 133 & 6.4 & 91 \\
\hline 2010 & 291 & 12.5 & 99 \\
\hline 2011 & 278 & 12.14 & 100 \\
\hline 2012 & 298 & 13.64 & 98 \\
\hline
\end{tabular}


Table 2. Social demographic characteristics of AFP cases reported and verified 2006-2012.

\begin{tabular}{|c|c|c|c|}
\hline \multirow{2}{*}{$\begin{array}{l}\text { Age (months) } \\
\text { Less than } 60\end{array}$} & \multirow{2}{*}{$\begin{array}{c}\text { Reported (\%) } \\
1004(84.8)\end{array}$} & \multicolumn{2}{|c|}{ Verified (\%) } \\
\hline & & 835 & -94.4 \\
\hline $60-120$ & $161(13.6)$ & 44 & -4.9 \\
\hline $120-180$ & $19(1.6)$ & 6 & -0.7 \\
\hline \multicolumn{4}{|l|}{ Sex distribution } \\
\hline Male & $582(49.2)$ & 433 & -48.9 \\
\hline Female & $602(50.8)$ & 452 & -51.1 \\
\hline \multicolumn{4}{|l|}{ Setting (Urban-Rural) } \\
\hline Urban & $197(16.6)$ & 139 & -15.7 \\
\hline Rural & $987(83.4)$ & 746 & -84.3 \\
\hline \multicolumn{4}{|c|}{ Educational attainment of caregivers } \\
\hline None & $598(50.5)$ & 446 & -50 \\
\hline Primary & $303(25.6)$ & 227 & -26 \\
\hline Secondary & 236 (19.9) & 176 & -20 \\
\hline Tertiary & $47(4.0)$ & 35 & -4 \\
\hline \multicolumn{4}{|c|}{ Vaccination status (OPV in doses) } \\
\hline 0 & $36(3.0)$ & 27 & -3 \\
\hline $1-2$ & $172(14.5)$ & 128 & -14.5 \\
\hline 3 & $266(22.5)$ & 196 & -22.2 \\
\hline$>3$ & $710(60.0)$ & 534 & -60.3 \\
\hline \multicolumn{4}{|l|}{ Informant } \\
\hline Focal person & $520(43.9)$ & 389 & -43.9 \\
\hline Other health workers & 437 (36.9) & 327 & -36.9 \\
\hline Parents/Caregiver & $227(19.2)$ & 169 & -19.2 \\
\hline \multicolumn{4}{|c|}{ Time specimen arrived the laboratory } \\
\hline Less than 72 hrs & 1112 (93.9) & 831 & -93.9 \\
\hline Greater than $72 \mathrm{hrs}$ & $72(6.1)$ & 54 & -6.1 \\
\hline \multicolumn{4}{|c|}{ Immunization card retention } \\
\hline Yes & $803(67.8)$ & 600 & -67.8 \\
\hline No & $381(32.2)$ & 285 & -32.2 \\
\hline \multicolumn{4}{|c|}{ Home to clinic distance (Kilometre) } \\
\hline $1-5$ & $901(76.2)$ & 720 & -81 \\
\hline $6-10$ & $186(15.7)$ & 120 & -14 \\
\hline Greater than 10 & $97(8.1)$ & 45 & -5 \\
\hline
\end{tabular}

In total, AFP Focal Person reported 389/885 (43.9\%) of case verified, this was followed by the 327/885 (36.9\%) reported by other health workers, parents/caregivers reported 169/885 (19.2\%).

The transportation of AFP stool specimens using the reverse cold chain also indicates that 831/885 (93.9\%) of stool specimens arrived the laboratory within 72 hours from time of collection of the second stool specimen (target $\geq 90 \%$ ). However, 54/885 (6.1\%) arrived the laboratory after 72 hours.

Immunization card retention also varied among the cases verified, while $67.8 \%$ had vaccination card $32.2 \%$ reported missing or destruction of vaccination cards.

Majority of AFP cases $81.0 \%$ resides within 5 kilometres radius to clinic or health centres were immunization and other health care services is received. However, $14.0 \%$ of the cases reside between 6 - 10 kilometres radius and $5.0 \%$ travel distances more than 10 kilometres radius to received immunization services 
Table 3 shows the clinical characteristics of AFP cases reported, investigated and verified.

Overall, $743 / 885(84.0 \%)$ were reported within $\leq 14$ days of paralysis onset, while 142/885 (16.0\%) were reported after $\geq 14$ days of paralysis onset. In total, 797/885 (90.0\%) of cases were found to have fever at the onset of paralysis, paralysis was found to be asymmetric in 805/885 (91.0\%). Wasting (hypotonia) or diminished muscle tone was observed in $34.0 \%$ of cases verified, while deep tendon reflexes were good (normal) in $79.0 \%$ of cases.

The most common preliminary diagnosis of AFP cases was Gullain-Barre syndrome (34\%), followed by injection neuritis (25.0\%) and transverse myelitis (2.0\%). However, other causes recorded 39.0\%. The legs were affected in $90.0 \%$ and the arm in $10 \%$ of the AFP cases reported and verified.

Figure 1 Compare case reported against verified from January 2006 to September 2012.

Study results show a steady increase in cases reported and verified from 2006 to 2010. However, a decline in number of cases reported and verified declined in 2011 and 2012.

There was steady increase in the proportion of reported cases verified by World Health Organization Officers in the state, from $23.0 \%$ in 2006 to $94.0 \%$ in 2012.

Table 3. Clinical characteristics of AFP cases reported, investigated and verified.

\begin{tabular}{|c|c|c|}
\hline & Reported (\%) & Verified (\%) \\
\hline \multicolumn{3}{|c|}{60 days follow-up residual paralysis } \\
\hline Yes & $89(7.5)$ & $72(3.1)$ \\
\hline No & 1095 (92.5) & 813 (91.9) \\
\hline \multicolumn{3}{|c|}{ Number of limbs affected* } \\
\hline 1 & $592(50.0)$ & $343(39.0)$ \\
\hline 2 & $545(46.0)$ & $407(46.0)$ \\
\hline 3 & $12(1.0)$ & $9(1.0)$ \\
\hline 4 & $36(3.0)$ & $27(3.0)$ \\
\hline \multicolumn{3}{|c|}{ Clinical syndrome at onset } \\
\hline Fever present & $1066(90.1)$ & $796(90.0)$ \\
\hline No fever & $118(9.9)$ & $89(10.0)$ \\
\hline \multicolumn{3}{|l|}{ Asymmetric paralysis } \\
\hline Yes & 1077 (90.9) & $805(91.0)$ \\
\hline No & $107(9.1)$ & $80(9.0)$ \\
\hline \multicolumn{3}{|l|}{ Muscle tone } \\
\hline Normal & $781(65.9)$ & $584(66.0)$ \\
\hline Abnormal & $403(34.1)$ & $301(34.0)$ \\
\hline \multicolumn{3}{|l|}{ Reflexes } \\
\hline Normal & 935 (78.9) & $699(79.0)$ \\
\hline Abnormal & $249(21.1)$ & $186(21.0)$ \\
\hline \multicolumn{3}{|l|}{ Working diagnosis } \\
\hline GBS & 603 (50.9) & $301(34.0)$ \\
\hline Injection neuritis & $295(25.0)$ & $221(25.0)$ \\
\hline Transverse myelitis & $24(2.0)$ & $18(2.0)$ \\
\hline Others & $262(22.1)$ & $345(39.0)$ \\
\hline \multicolumn{3}{|c|}{ Parts of the limb affected } \\
\hline Right upper limb & 47 (3.9) & $35(4.0)$ \\
\hline Left upper limb & $71(5.9)$ & $53(6.0)$ \\
\hline Right lower limb & $521(44.1)$ & $389(44.0)$ \\
\hline Left lower limb & $545(46.1)$ & $408(46.0)$ \\
\hline
\end{tabular}

${ }^{*}$ missing data. 


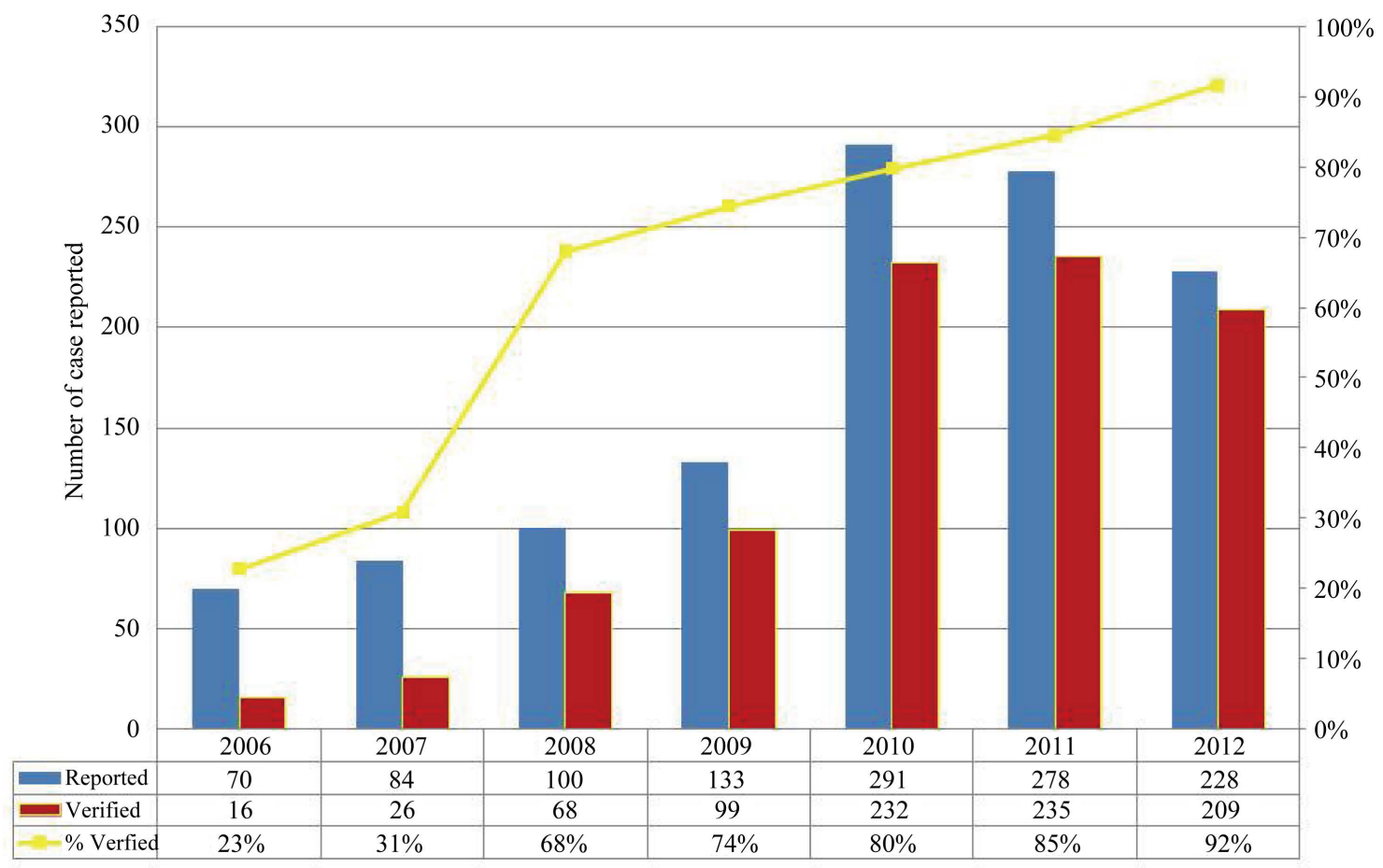

Figure 1. Comparing number of cases reported against verified 2006-2012.

\section{Discussion}

Detecting and investigating all cases of non-polio AFP in the population $<15$ years old are among the most important criteria for poliomyelitis-free certification. In polio-free countries, the incidence of AFP is expected to be at least $\geq 1$ per 100,000 children aged $<15$ years old [7]. The results of this study indicated that active surveillance of AFP was efficient over the past six consecutive years and even exceeded the WHO-established minimum non-polio AFP rate. In addition, the second criteria of AFP surveillance, adequate collection of two stool specimens within 14 days of the onset of paralysis in at least $80 \%$ of detected AFP cases [7], was achieved efficiently as well.

Three age categories were incorporated in the study, aged less than sixty months, sixty to one hundred and twenty months and one hundred and twenty one to one hundred and eighty months. In this study, the proportion of AFP cases $84.8 \%$ recorded in children aged 5 years and below was lower than the $90.0 \%$ that reported in India [8]. Similarly, another study in Ibadan, south western Nigeria also reported a lower prevalence $43.0 \%$ among this age group of children [9], while a much lower prevalence of 37.0\% was also reported in Marches region, Italy [10], also in Amritsar, India other workers also reported 58.7\% also in children aged 5 years and below [11]. Elsewhere in Korea $54.0 \%$ was also reported [12]. The reason for these variations may be attributed in surveillance sensitivity and type of surveillance practiced (active or passive).

Regarding sex or sex distribution most of the cases seen in the study were in female children (50.8\%), similar results were also demonstrated in Ido Ekiti, Nigeria and Abbottabad, Pakistan within the same study group [13] [14].

Most parents and caregivers lacked formal education, Lack of education may lead to of misconceptions, and is generally known there are associations between vaccine uptake and education level of parents, especially of mothers. According to Buor's study (2003) examining the impact of mothers' education on childhood immunization status in Ghana, $86.7 \%$ of mothers with secondary education or above immunized their child, whereas for mothers without formal education, this was only $42.2 \%$ [15]. Thus, education levels of parents may well have been one of the key reasons for the poor routine immunization uptake thus leading to high number of AFP cases.

Oral Polio Vaccine (OPV) coverage among AFP cases varied among the population studied, ranging from $3.0 \%$ in zero dose cases, $14.5 \%$ in those that received $1-2$ doses of OPV and $82.5 \%$ in those that received $\geq 3$ doses OPV. It is important to note that lowered immunization coverage as indicated in $17.5 \%$ of the studied 
population may also have serious consequences in countries that use OPV, as was recently demonstrated by outbreaks of poliomyelitis due to circulating vaccine derived polioviruses (cVDPV) in Nigeria [16]. Overall, routine immunization ranged from $51 \%$ to $77 \%$ in 2012 .

AFP surveillance depends on the following main system elements: 1) immediate reporting and investigation of AFP cases; 2) routine monthly negative reporting ("zero" reporting even if no AFP case is seen) from all health facilities; and 3) weekly active surveillance visits to priority health facilities and other reporting sites likely to see AFP cases [17]. AFP surveillance systems in industrialized and many middle-income countries are integrated into existing disease surveillance systems and are run by national health staff. In developing countries with fewer resources, a network of surveillance officers (SOs) was put in place to ensure that the system performs adequately. Linkages between public health workers and clinicians are established through frequent activities to inform and sensitize clinicians. In countries with weak health systems, efforts are made to involve the informal health sector (traditional healers, traditional birth attendants, and patent medicine vendors), communities and community informants in reporting AFP cases. In this study key informants include health care workers who reported $80.8 \%$ of the AFP cases recorded. The community (parents/caregivers) reported only $19.2 \%$ of the cases. This is an indication that there is weak involvement of the community in the surveillance network; community-based systems, community members should receive basic education or more extensive training to motivate and enable them to notify health care workers about possible cases of disease in a timely fashion. This can improve the level of comprehensiveness and sensitivity of surveillance.

Two essential steps need to be taken to establish the foundations of such participation. The first important step is to recruit, train, supervise and motivate a corps of community health agents [18]. These community agents can play different roles, including conducting campaigns of awareness and motivating parents to report early suspected cases of AFP in their households. Community agents should also keep their eyes and ears open and report suspected cases on their own, especially when they suspect that parents would not, as a result of their cultural beliefs and/or lack of access to transportation or communication with an epidemiologist [18].

The second important step is to develop linkages and collaborations among various community opinion leaders and interest groups to improve the sensitivity of AFP surveillance at the peripheral and local levels. Traditional healers who treat paralyzed children, local midwives who deliver babies and follow their growth, and community health agents who disseminate health information are all involved in providing health care. It would be useful for epidemiologists to partner these individuals, who are likely to encounter or know about AFP cases. Local healers, in particular, earn their living trying to treat diseases such as paralysis, and may find it disadvantageous to refer cases to the local clinics, thereby losing their clients. It is therefore important to find ways of reassuring them, perhaps through compensation, to turn them into reliable and effective allies. Providing rewards to community members who reported cases and to health workers who confirmed them was critical in the smallpox-eradication campaigns [18].

The World Health Organization recommends two faecal specimen collected at least 24 hours apart, both within 14 days of paralysis onset and arriving at the laboratory in "good" condition (With sufficient volume ( $\geq 8$ grams) and fully transported under cold conditions (ice/frozen icepack present in transport container or temperature indicator showing constant temperature $\leq 8^{\circ} \mathrm{C}$ ) in appropriate containers without evidence of leakage or drying, and accompanied by appropriate documents), within 72 hours after collection of the second stool specimen. In this study, $93.9 \%$ of stool specimen collected arrived the laboratory in good condition (target $\geq 80 \%$ ), an indication of good reverse cold chain, providing the greatest chance of isolating polio virus [6].

In this study, we evaluated immunization card retention among AFP cases reported. The $67.8 \%$ immunization card retention recorded in this study is lower than what is reported in other developing countries such as $8.0 \%$ in Sierra Leone [19], 84.7\% in Aden, Yemen [20], 84.0\% in Dhaka district [21], elsewhere in Edo state south-south Nigeria 55.5\% was reported [22]. The reason for the variation seen in data reported from different countries may be attributed to variation in differences in immunization policies and programmes, access to health care facilities, lack of qualified personnel, availability of appropriate vaccines, or logistics challenges involved in reaching the population that is over $80.0 \%$ rural with vaccines and other interventions [22].

Distance to health services impacts on health seeking behaviours [23]. Travel times, lack of access to transportation, and seasonally inaccessible roadways can present barriers to patient access to health facilities [23]. Areas of low access are often inhabited by people who need healthcare the most [23]. All residents in areas where access is difficult often under-utilize services or present to health facilities (HF) only when their condition is grave, sometimes missing opportunities to effectively treat health problems [23]. Distance to HFs may also 
negatively impact disease prevention. For malaria in particular, remoteness and proximity to HFs have been shown to be associated with ITN possession in Kenya [23]. This study has clearly shown that fewer AFP cases were detected in settlements beyond 5 kilometres radius, this underscore the need for establishment of health facility within 5 kilometre radius.

The following cases the children undergoes a 60-day follow-up examination: 1) cases with inadequate or no stool specimens; 2) cases with isolation of vaccine virus from the stool; 3) cases with isolation of wild poliovirus from the stool; and 4) any case that the investigator thought was strongly suggestive of poliomyelitis on initial examination ("hot case"). On sixty-day follow-up, the child is assessed for weakness, asymmetrical skin folds, and difference in left/right mid-arm/mid-thigh circumference [24]. The child is considered to have residual weakness if any of the above is present, even if minimal. The finding of residual weakness on follow-up is suggestive that the case may actually be polio, and this information is taken into account during final case classification. 60-day follow-up of children from whom wild poliovirus was isolated allows the investigator to assess the community for evidence of ongoing wild virus transmission, by searching for additional AFP cases. In this study $7.5 \%$ of the cases had inadequate stool specimen requiring 60 days follow up examination for the presence of residual paralysis, while $92.5 \%$ (target $\geq 80.0 \%$ ) of the cases were reported within 14 days of paralysis onset. This indicated that the surveillance system is sensitive and has capacity to pick any case of wild polio virus.

Guillain-Barré syndrome is known as the major cause of non-polio AFP, particularly after the global eradication of poliomyelitis [25]. This syndrome was the most common cause of non-polio AFP cases and comprised $50.9 \%$ of all causes of AFP cases in the present study. A study conducted by Davarpanah et al. in 2008 [25] in Shiraz province, in central Iran, reported a similar result. They indicated that Guillain-Barré Syndrome was the main leading cause of AFP in $66.0 \%$ of the patients. Injection trauma or traumatic neuritis constitutes about a quarter of the AFP cases seen in this study, $25.0 \%$ of the children receive injection just before onset of paralysis. This high proportion of AFP cases due to injection neuritis may be attributed to poor injection administration techniques such as use of inappropriate dosage, route or poor storage condition of the vaccines.

Fever at the time of onset of paralysis is one of the cardinal symptoms of poliomyelitis [26]. In this study, fever was a major symptom in 90.1\% AFP cases seen; this is higher than the $62.0 \%$ in Pakistan [27], 53.4\% in south-west, India; 30.0\% reported elsewhere [25] has been reported India and 21.6\% in Hamadan, Iran [28]. The presence of fever in $90.1 \%$ cases in the present study may be attributed to the fact that majority of the cases was reported by clinics where cases when to seek health interventions.

Asymmetric paralysis was recorded in $61.2 \%$ of AFP cases in Raichur District, India [29]. In the present study, asymmetric paralysis at onset demonstrated higher percentage of $90.9 \%$.

In this study data collection were not randomized, it was rather based on the number of AFP cases reported, there were also missing information from the database.

\section{Conclusion}

Seventy-two percent (target $\geq 80.0 \%$ ) of the entire AFP cases reported in the surveillance network was verified by WHO officers. This suggested that the surveillance system was not performing optimally. The result further indicates that characterization of AFP cases reported could provide better understanding of age and sex distribution, and common causes of AFP. It is necessary to strengthen all components of AFP surveillance system including case detection, investigation, and verification, to ensure that the system is robust and sensitive enough to demonstrate the absence or circulation of wild poliovirus in the state.

\section{References}

[1] (2006) Anon: Global Polio Eradication Initiative. Bulletin of the World Health Organization, 84, 595.

[2] Watkins, R.E., Martin, P.A.J., Kelly, H., Madin, B. and Watson, C. (2009) An Evaluation of the Sensitivity of Acute Flaccid Paralysis Surveillance for Poliovirus Infection in Australia. BMC Infectious Diseases, 9, 162. http://dx.doi.org/10.1186/1471-2334-9-162

[3] Global Polio Eradication Initiative Annual Report 2007: Impact of the Intensified Eradication Effort. http://www.polioeradication.org

[4] CDC (2012) Progress toward Interruption of Wild Poliovirus Transmission—Worldwide, January 2011-March 2012. Morbidity and Mortality Weekly Report (MMWR), 61, 353-357.

[5] World Health Organisation (2009) Conclusions and Recommendations of the Advisory Committee on Poliomyelitis Eradication, November 2008. Weekly Epidemiological Record, 84, 17-28. 
[6] FMOH \& WHO (2007) Guidelines for Acute Flaccid Paralysis Surveillance in Nigeria.

[7] Dias Tosta, E. and Kückelhaus, C.S. (2002) Guillain Barre Syndrome in a Population Less than 15 Years Old in Brazil. Arq Neuropsiquiatr, 60, 367-373. http://dx.doi.org/10.1590/S0004-282X2002000300005

[8] Singh, K., Kaur, G. and Kumar, R. (2004) Acute Paralytic Poliomyelitis: Change in Number over Years Impact of PPI: Sentinel Centre Experience. Indian Journal of Community Medicine, 29, 82-83.

[9] Hamzat, T.K. and Omotade, T.T. (2006) Acute Flaccid Paralysis: A Five Year Review of Cases Managed by Physiotherapy at the University College Hospital, Ibadan. African Journal of Health Sciences, 13, 28-32.

[10] D’Errico, M.M., Barbadoro, P., Bacelli, S., Esposto, E., Moroni, V., Scaccia, F., Tantucci, L. and Prospero, E. (2008) Surveillance of Acute Flaccid Paralysis in the Marches Region (Italy): 1997-2007. BMC Infectious Diseases, 8, 135.

[11] Narang, G.S. and Pahwa J.S. (2011) Retrospective Study of Acute Flaccid Paralysis Cases from a Tertiary Care Centre in Amritsar. Pediatric Oncall. [Serial Online]

[12] Kim, H., Hwang, S., Kang, B., Cheon, D.S. and Kim, K. (2012) Acute Flaccid Paralysis (AFP) Surveillance in Korea during 10 Years (2002-2011). Global Vaccine Conference, 18 October 2012, San Diego, 4.

[13] Adelugba, J.K., Ayodiipo, I.O., Aladeyelu, O., Ogunbameru, T.D., Oni, O.A., Akinsiku, O.A. and Akinremi, A. (2011) Paediatric Neurological Conditions Seen at the Physiotherapy Department of Federal Medical Centre, Ido Ekiti, Nigeria: A Five Year Review. African Journal of Biomedical Research, 14, 183-186.

[14] Anis-ur-Rehman, Idris, M., Elahi, M., Jamshed and Arif, A. (2007) Guillain Barre Syndrome: The Leading Cause of Acute Flaccid Paralysis in Hazara Division. Journal of Ayub Medical College, Abbottabad, 19, 26-28.

[15] Buor, D. (2003) Analysing the Primacy of Distance in the Utilization of Health Services in the Ahafo-Ano South District, Ghana. International Journal of Health Planning and Management, 18, 293-311. http://dx.doi.org/10.1002/hpm.729

[16] Centers for Disease Control and Prevention (2010) Progress toward Poliomyelitis Eradication in Nigeria, 2009. Morbidity and Mortality Weekly Report, 59, 545-550.

[17] Canada Communicable Disease Report (CCDR). CCDR 2004: Volume 30. International Note-Acute Flaccid Paralysis Surveillance: A Global Platform for Detecting and Responding to Priority Infectious Diseases.

[18] Ndiaye, S.M., Quick, L., Sanda, O. and Niandou, S. (2003) The Value of Community Participation in Disease Surveillance: A Case Study from Niger. Health Promotion International, 18, 89-98. http://dx.doi.org/10.1093/heapro/18.2.89

[19] Senessie, C., Gage, G.N. and von Elm, E. (2007) Delays in Childhood Immunization in a Conflict Area: A Study from Sierra Leone during Civil War. Conflict and Health, 1, 14. http://dx.doi.org/10.1186/1752-1505-1-14

[20] Basaleem, H.O., Al-Sakkaf, K.A. and Shamsuddin, K. (2010) Immunization Coverage and Its Determinants among Children 12-23 Months of Age in Aden, Yemen. Saudi Medical Journal, 31, 1221-1226.

[21] Khan, M.N., Rahman, M.L., Awal Miah, A., Islam, M.S., Musa, S.A. and Tofail, F. (2005) Vaccination Coverage Survey in Dhaka District. Bangladesh Medical Research Council Bulletin, 31, 46-53.

[22] Odusanya, O.O., Alufohai, E.F., Meurice, F.P. and Ahonkhai, V.I. (2008) Determinants of Vaccination Coverage in Rural Nigeria. BMC Public Health, 8, 381. http://dx.doi.org/10.1186/1471-2458-8-381

[23] Gething, P.W., Noor, A.M., Zurovac, D., Atkinson, P.M., Hay, S.I., Nixon, M.S. and Snow, R.W. (2004) Empirical Modelling of Government Health Service Use by Children with Fevers in Kenya. Acta Tropica, 91, 227-237. http://dx.doi.org/10.1016/j.actatropica.2004.05.002

[24] World Health Organization and India National Polio Surveillance Project. www.npspindia.org

[25] Dietz, V., Andrus, J., Olive, J.M., Cochi, S. and de Quadros, C. (1995) Epidemiology and Clinical Characteristics of Acute Flaccid Paralysis Associated with Non-Polio Enterovirus Isolation: The Experience in the Americas. Bulletin of the World Health Organization, 73, 597-603.

[26] Davarpanah, M.A., Bakhtiari, H., Mehrabani, D. and Khademolhosseini, F. (2008) A 12-Years Surveillance of Poliomyelitis and Acute Flaccid Paralysis in Fars Province, Southern Iran. Iranian Red Crescent Medical Journal, 10, 288293.

[27] Kapoor, A., Ayyagari, A. and Dhole, T.N. (2001) Non-Polio Enteroviruses in Acute Flaccid Paralysis. Indian Journal of Pediatrics, 68, 927-929. http://dx.doi.org/10.1007/BF02722583

[28] Poorolajal, J., Ghasemi, S., Farahani, L.N., Hosseini, A.S., Bathaei, S.J. and Zahiri, A. (2011) Evaluation of Acute Flaccid Paralysis in Hamadan, Iran from 2002 to 2009. Epidemiology and Health, 33.

[29] Patil, V., Surpur, R.R., Anitha, M.R. and Vijayanath, V. (2013) Study of Prevalence of Non-Polio Enteroviruses in Children of 0-15 Years of Raichur District. Journal of Pharmaceutical and Bioanalytical Science, 2, 1-12. 
Scientific Research Publishing (SCIRP) is one of the largest Open Access journal publishers. It is currently publishing more than 200 open access, online, peer-reviewed journals covering a wide range of academic disciplines. SCIRP serves the worldwide academic communities and contributes to the progress and application of science with its publication.

Other selected journals from SCIRP are listed as below. Submit your manuscript to us via either submit@scirp.org or Online Submission Portal.
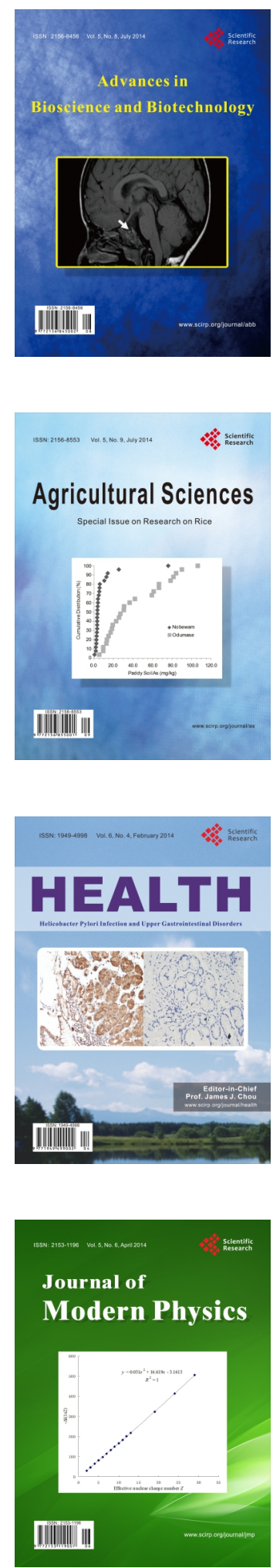
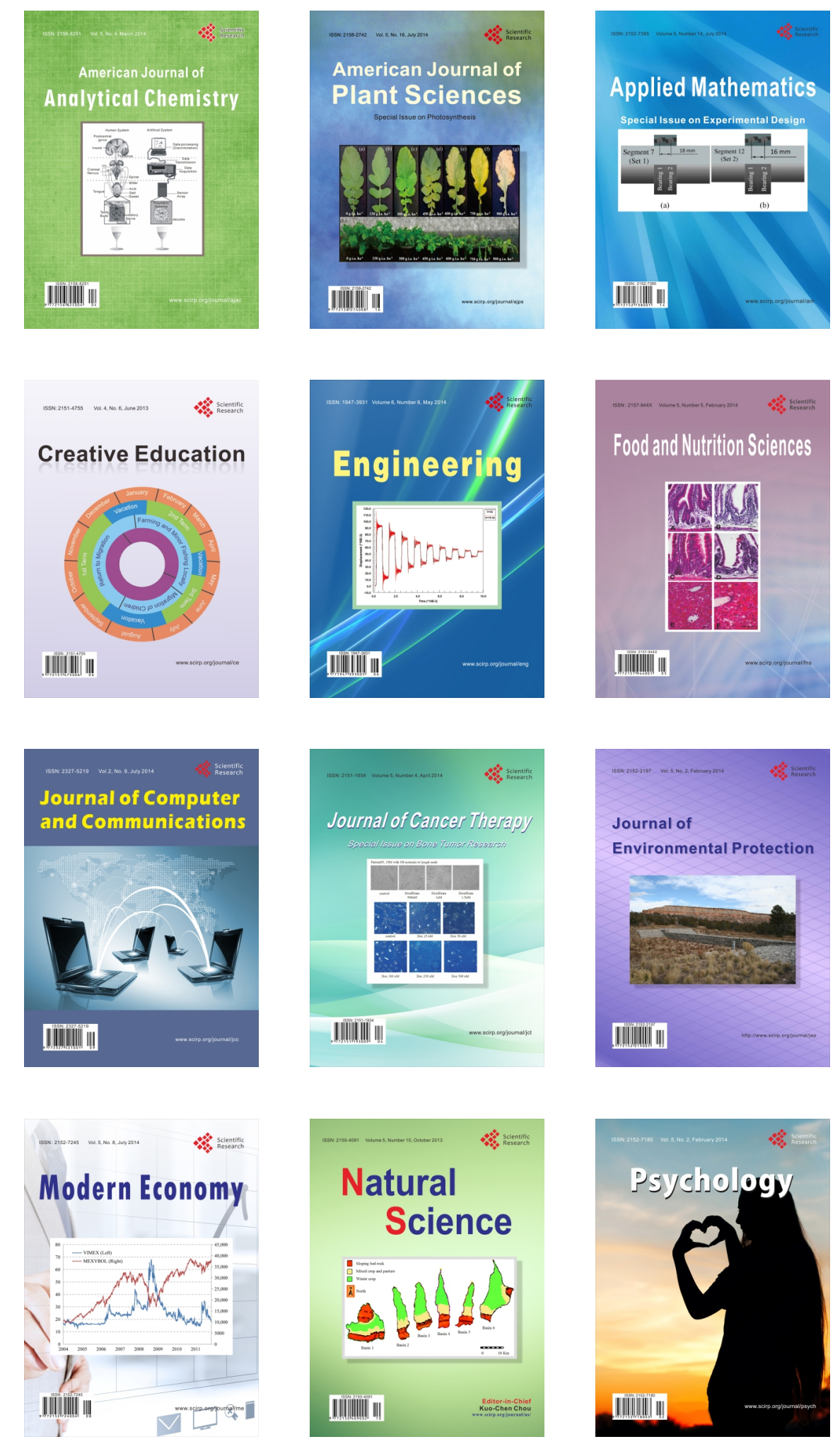